\title{
DOS MODELOS LINGÜÍSTICOS DIFERENTES: JUAN RUIZ Y DON JUAN MANUEL
}

\author{
Manuel Alvar
}

Para Alberto Vàrvaro

\section{INTRODUCCIÓN}

Trazar la historia lingüistica, o la historia literaria, es algo más que análisis lineales. Creo que resulta más eficaz hacer unos cortes transversales que permitan ver - como en biología - el funcionamiento de las estructuras. $\mathrm{Y}$, a través de los análisis lingüísticos, podremos acercarnos, con una seguridad mayor de lo que habitualmente se hace, a conocer la razón de la obra literaria. Voy a ejemplificar con dos grandes escritores del siglo xiv. El Arcipreste de Hita coincide con don Juan Manuel en el tratamiento de cuatro apólogos: el de la avutarda y la golondrina, el del raposo que se finge muerto, el de la zorra y el cuervo y el del ladrón que hizo carta al diablo. Comparémoslos ${ }^{1}$.

\section{El ejemplo de la golondrina y el campo de cáÑamo (o lino)}

Las estrofas 746-754 narran el primer enxiemplo, y se corresponden con la página 78 del Conde Lucanor. Si hacemos un esquema veremos con claridad cómo el mismo argumento es tratado de manera harto diferente ${ }^{2}$ :

1 Sigo las ediciones de Corominas (Madrid, 1973) y Blecua (Don Junn Manuel, Obras Completas, t. II, Madrid, 1983). Los números que ponemos en el Libro de Buen Amor se refieren a la estrofa del texto; los del Conde Lucanor, a la línea. No es de mi incumbencia ahora plantear los criterios de edición. Los encomiables esfuerzos de G. Chiarini fueron apasionadamente defendidos por Oreste Macrf, Ensayo de métrica sintagmática, Madrid, 1969, págs. 11-39. Sobre el método, vid. Alberto Blecun, Manual de critica textwal, Madrid, 1973.

2 Cfr. Reinaldo Ayerbe-Chaux, El Conde Lucanor, Madrid, 1975, págs. 59-64. Tampoco toca las líneas que me interesan VitTorio Marmo, Dalle fonti alle forme. Studi

LXVIII, $1 .^{\circ}-2 .^{\circ}-2$ 
Libro de Bwen Amor

Un cazador siembra cañamones para hacer cuerdas (746).

La avutarda estaba cerca del sendero (746).

La golondrina precave a tórtolas, pardales y a la propia avutarda (747).

Las aves se mofan de la golondrina (748).

Creció la semilla y el cazador la regaba (748).

La golondrina pide a la avutarda que arranque la hierba recién nacida, habida cuenta de los prolijos cuidados del cazador (749). La avutarda insulta a la golondrina (750).

La golondrina se fue a casa del pajarero, alli hizo su nido y cada mañana lo despertaba con sus gorjeos (751).

El lino es cogido y convertido en redes. Con ellas fue apresada la avutarda (752).

Los ballesteros le arrancaron para sus flechas las plumas de las alas y la asaron (753).
Conde Lucanor

La golondrina ve sembrar el lino y pensó que podrian hacerse con él redes y lazos (16-18).

Convoca a las aves para ponerlas sobre aviso (19-23).

Consideración moral (23-25).

Las aves no le hacen caso (25-26).

El lino, crecido ya, no se podía arrancar. Se arrepintieron las aves cuando ya no había remedio (28-33).

La golondrina se fue a casa del hombre y se le sometió. Por eso las golondrinas viven seguras $y$ las otras aves son cazadas (34-39).

Juan Ruiz ha pintado una bella escena en la que los recursos lingüisticos están sabiamente medidos: el cazador era un sotil pajarero que, en función de su oficio, sembraba cañamones y en un campo fértil. El cuadro se completa : una avutarda contempla la escena; la golondrina avisa a todas las aves, no sólo a la que ha visto la siembra, y el relato cobra un dramático sesgo con el estilo directo que se transcribe. Se vuelve al estilo indirecto libre (dexieronle que) y el narrador prosigue el relato con la subordinación a un verbo dicendi ("dixo que arrancase la yerva"); la respuesta de la avu-

sul "Libro de Buen Amor", Nápoles, 1983. Los análisis de este autor son totalmente distintos de los míos. Añádanse los informes de Daniel Devoto, Introducción al estudio de don Juan Manuel y, en particular, de "El Conde Lucanor". Una bibliografía, Madrid, 1972, págs. 372-375. 
tarda se reproduce fielmente, y con una angustiada imprecación (Juan Ruiz transcribe simplemente las injurias y la autosuficiencia de la avutarda). La golondrina desasistida marcha a casa del cazador: el Arcipreste ajusta su vocabulario a un mundo de precisiones en el que son descritos el nido de la golondrina, las condiciones del ave y se hace un escueto retrato del hombre. Tras estos preámbulos necesarios, la conclusión ejemplar (captura de la avutarda y presencia de la golondrina en un breve pasaje de estilo directo). Después, la cauda de una escena amargamente burlesca: la avutarda en la plaza es desplumada para hacer flechas con sus plumas largas y le dejan unas escasas y cortas que luego le chamuscaron.

El cuadro es justo: con léxico preciso en los metalenguajes (pasarero, cazador, redero, cuerdas, lazos, tórtolas, pardales, chirlar, gorjeador, vicioso ero ${ }^{3}$, cañamón, regar, arrancar, pujar, escardar), en el empleo de fraseología (jvete para villana!) y en el escarnio del desplume. El léxico es eminentemente popular, según conviene a la descripción; los cultismos, escasos, están bien adaptados (tórtola, cáñamo) y los sufijos empleados según una tradición bien documentada: -ero, con formas de masculino y femenino (redero, gritadera), -or como forma única (gorjeador, madrugador). Más aún, el antagonista del relato es una avutarda en la que Juan Ruiz pone su experiencia de buen observador: las avutardas no se encuentran ni en bosques, ni en sitios habitados por el hombre, por eso andaba cerca en el sendero, caminan lentamente y se remontan con gran trabajo (fácil presa para el trampero), se alimentan de plantas verdes y granos tiernos (por eso la recomendación de la golondrina) 4 .

Don Juan Manuel se queda en un plano general (aves, frente a avutarda, tórtola o pardal; hombre frente a pasarero, cazador o redero) en el que se desarrollan los procesos intelectuales ("la golondrina vido... et entendio, por el su buen entendimiento"), que permiten las deducciones lógicas ("se les seguiría ende muy grant danpno et que les consejaua que ..."). Por eso el narrador no se hunde en un plano de precisiones como ha hecho Juan Ruiz, sino que se abroquela en sus admoniciones ("las cosas son ligeras de se desfazer en el comienço et despues son muy mas graues de se desfazer. Et la golondrina les afinco desto muchas veces") que acaban por ser aceptadas, cuando ya no tienen remedio ("el repintimiento fue a tienpo que non podian tener ya pro"). Para el moralista que era don Juan Manuel, culpa

s Debe corregirse el DCELC, s.v. era II, pues los eriales del 747 son ero 'campo', y campo cultivado: vicioso ero (746 b), semiente... sembrada (747 c-d) y cultivada con esmero (748 c $749 c$ ).

-Vid. las atinadas observaciones de Marfa Rosa Lida de Malkirl, en Two Spanish Masterpieces: The "Book of Good Love" and "The Celestina", Urbana, 1961, pág. 27. 
y arrepentimiento van emparejados y se dan en el alma de cada uno; para Juan Ruiz, no hay arrepentimiento, sino que cada cual vive su propia inconsciencia. De este modo, el Infante expone un discurso ético, y el Arcipreste la experiencia vital sin moralina; por eso, cuando la avutarda es capturada, la golondrina se alegra: "ya sodes en pelaça" ". Ni compasión para el pecador, ni dolor por el pecado. Don Juan Manuel ha narrado el ejemplo desde fuera y todo él es como un ascético sermón; Juan Ruiz ha descrito un cuadro ajeno a su propia condición y sólo al final pondrá un verso de exhortación a doña Endrina. Por eso no valen para el prosista todas las consideraciones que hemos hecho sobre la lengua del poeta: una limpia objetividad relata un hecho lógico, incluso al desplazar al final del relato la convivencia de hombres y golondrinas, que en Juan Ruiz se ofrecía como testimonio de vitalidad enmarañada.

\section{EJEMPLO DEL RAPOSO ROBADOR}

Tras los consejos de Trotaconventos para amar a una mujer, vienen una serie de ejemplos entre los que se cuenta el "de la raposa que come gallinas en la aldea", que tiene su correspondencia con el ejemplo XXIX del Conde Lucanor (págs. 252-253 de la edición que manejo). He aquí el esquema de ambos:

\section{Libro de Buen Amor}

Una zorra visitaba asiduamente una aldea y se comía las gallinas de todas las casas (1412).

Los del pueblo le cerraron todas las salidas (1413).

La zorra se hizo la muerta (1414).

Los viandantes se mofaban (1414).

\section{Conde Lucanor}

Un zorro entró una noche en un corral (19-20).

Se hizo de día y no pudo escapar (21).

Se tendió haciéndose el muerto (2224).

Nadie le hizo caso (25-26).

Un hombre le cortó los pelos de la frente (27-29), otro los del lomo, otro los de las ijadas (31-34), otro le arrancó una uña (36-37),

\footnotetext{
5 Prefiero esta lectura a plasa. Es mucho más coherente con el relato y más eficaz literariamente hablando (vid. Margherita Morreale, Apuntes para un comentario literal del "Libro de Buen Amor", "Boletín Real Acad. Esp.", XLIII, 1963, página 303).
} 


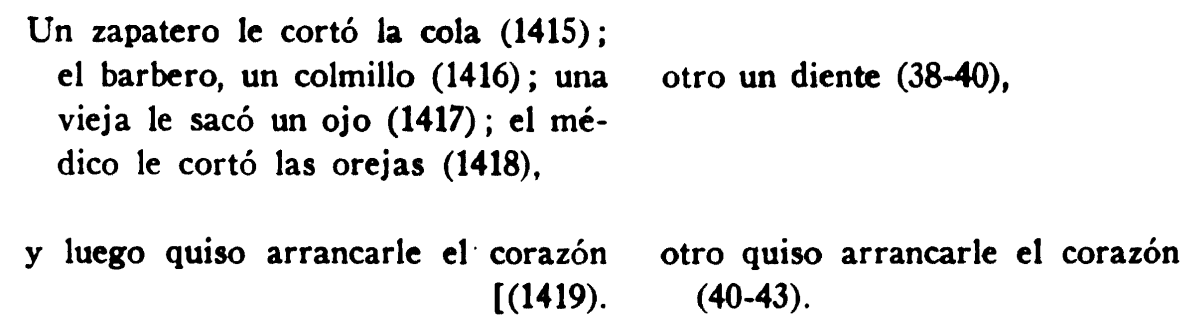

Entonces la zorra se levantó y huyó Entonces se escapó (47-48). (1420).

Los planteamientos son muy parecidos a los del ejemplo anterior. En don Juan Manuel, todo tiene un desarrollo lineal, sin ninguna clase de complicación: la zorra va a un corral, con el trajín del gallinero se le hizo de día y no pudo escapar, pues las calles ya se habían poblado; entonces se fingió muerta, sin que nadie la tomara en consideración hasta que le cortaron cerdas de la frente para evitar el mal de ojo a los niños pequeños; después, otro hombre le cortó unos pelos y otro le arrancó un diente para remediar el dolor de muelas y otro - por último- le quiso sacar el corazón para curar estas dolencias. Fue entonces cuando la zorra se atrevió a dejar el fingimiento y pudo escapar. Son veinte líneas muy escuetas. Frente a ellas, Juan Ruiz escribe 36 alejandrinos llenos de lozanía y amplificaciones. Porque la zorra, según acostumbra, va a una aldea de muro bien cercada, entraba por la noche y pasaba de casa en casa haciendo tropelías. No es, como en don Juan Manuel, un fortuito azar el que impide la huída, sino la consideración activa de quienes se consideraban burlados por eso, tras la afrenta repetida, planean el modo de capturar a la zorra. El fingimiento es perfecto ${ }^{6}$; la boca regañada, las manos encogidas, el cuerpo yerto, cualquier cosa menos aparentar vida. $\mathrm{Y}$ viene a continuación el desarrollo puntual de unas escenas que llevan al mismo fin que en el Conde Lucanor, pero ahora muy lejos de cualquier frío enunciado: se transcriben fielmente las palabras del zapatero, del barbero, de la vieja, del médico y las íntimas consideraciones de la zorra. El Arcipreste ha conseguido transmitir las secuencias de un cuadro espléndido: la vida mañanera se inicia, los menestrales que van o que vienen de su quehacer ("el alfajeme pasava, que venía de sangrar"), la comadre que deambula. Todo está logrado y bellamente dicho. No cabe duda: el pueblo tiene su pulso y la vida, abigarrada, fluye, la manifestación lingüistica se despliega para conseguir unos cuadros de género: el zapatero quiere preparar trainel; el barbero aprovecha el colmillo de la zorra para curar el dolor de quijada; la vieja emplea el ojo para remediar

- Cfr. Devoro, op. cit., págs. 416-417, y bibliografía que este autor aduce en la pág. 417. 
la histeria y el mal de ojo; el médico recurre a las orejas de la zorra para curar el dolor de oido. Diriamos que una vieja tabla nos va dando el ambiente: la aldea tiene un muro de defensa, con una puerta grande que se cierra al anochecer, y otras pequeñas; se ven un callejón y un camino de ronda; en ellos, casas, con ventanas y gateras. Cada vecino se siente burlado (malchufado) y quiere vengarse ("una vieja passava, que l' comió su gallina"), quien más quien menos saca provecho de aquel astuto animal que está muerto en la calleja : con los dientes salidos, engurruñadas las patas, rígido por el frío e irreconocible. La representación es un prodigio y sigue la viveza del estilo directo, las bromas de quienes ya pueden respirar tranquilos (“i Tente esa trasnochada!”), la eficacia del exabrupto (“ $\mathrm{Al}$ diablo catedes vos el polso!") o la sabiduría del refrán ("lo qu'enmendar non se puede, non presta arrepentir"). El vocabulario mana irrestañable, con una inigualable exuberancia: la zorra es gulhara, golpeja, raposo; el léxico popular está presente en el debido momento (escotado, malchufado, moças aojadas, coso, presta, etc.); los arabismos, en el vocabulario de las ocupaciones (zapatero, alfajeme) o en los adjetivos (mezquina), y los galicismos (trainel) o los cultismos (físico, tremer), y otras tantas ordenaciones en que pudiéramos clasificar los elementos que configuran el precioso fragmento.

Don Juan Manuel ha vuelto a quedarse en un plano que no desciende al relato pintoresco: hombres, sin precisar, van mutilando al animalejo; hay, también, un planteamiento intelectual de los hechos ("quando él cuydó que se podría yr [...] et desque él vio que non se podía asconder", "touo que era meior de se aventurar") que alejan la curiosidad de un hecho que se ofrece como normal ("quando las gentes lo vieron, cuydaron que era muerto, et non cató ninguno por él"). Y el vocabulario que hace falta a la exposición: preciso, pero sin estridencias de ningún tipo. Juan Ruiz, una vez más, se ha metido en estos cuadros, los ha hecho vivir porque él es cada uno de sus personajes, en el estilo directo, en el conocimiento de cada actividad, en el habla que en cada momento se usa. Su cuento son unos cuantos retazos de vida; don Juan Manuel -desde su lejanía- expone y narra objetivamente?

\section{EJEMPLO DE LA ZORRA Y EL CUERVO}

El tercer relato que voy a considerar es el que Juan Ruiz llama Enxiemplo de la raposa y el cuervo (cuadernas 1437-1444) y don Juan Manuel,

7 Nada tienen que ver con estos hermosos relatos las dos fabulillas de Odon de Cheriton sobre el zorro que se fingió muerto (Hervieux, IV, págs. 220, 303). Confrontar AYERbe-ChauX, págs. 66-69. 
De lo que contesçió a un raposo con un cueruo que tenie un pedaço de queso en el pico (págs. $71-74)^{8}$. He aqui su $\operatorname{cotejo}^{\circ}$ :

Libro de Buen Amor

Un día estaba hambrienta la zorra $y$ vio en un árbol al cuervo con un pedazo de queso en el pico, y lo saludó con adulaciones (1437).

Lo compara con el cisne por su blancura y a las aves cantoras por sus gorjeos.
Escuchándolo se encontraría libre de pesares (1439).

El cuervo, hinchado de placer, comenzó a cantar; se le cayó el queso que se comió la zorra. Con lo que el ave quedó entristecida (1441).

\section{Conde Lucanor}

Un cuervo se encontró un gran pedazo de queso y se subió a un árbol para comerlo tranquilamente. Así las cosas, pasó un raposo que comenzó a pensar cómo podría hacerse con el manjar (22-27).

Para ello el zorro urdió su plan: había oído hablar de las buenas prendas del cuervo y, para comprobarlas, lo había buscado ahincadamente. $Y$ ahora se da cuenta de cuán cierto es cuanto había oído. Más aún, para que no suene a lisonja, le dirá también qué hay en él que no merezca elogio (28-36). Las plumas negras no son feas, sino que merecen ser dignas de un pavón, la más bella de las aves (37-45). Los ojos negros son los más hermosos y parecen de gacela (45-50). Pico y uñas son mejores que los de ningún ave semejante (50-52). En el vuelo aventaja a todos (52-54). Y, si Dios lo ha dotado de tan altas prendas, es de suponer que lo haya hecho gran cantor (52-58).

$$
\text { Anhelaria escucharle (58-61). }
$$

Las comparaciones se habian hecho sobre referencias ciertas y el cuervo pensó que el zorro era su amigo (6769). Al no sospechar el engaño, abrió el pico, cayó el queso, y se lo llevó el zorro (70-76).

\footnotetext{
8 El relato duraba todavía en nuestra literatura clásica, cfr. Maxime Chevalier, Cuentos folklóricos españoles del siglo de oro, Barcelona, 1983, pág. 29.

- Los ejemplos fueron analizados por Menéndez Pidal en una Nota sobre una fábula de don Juan Manuel y de Juan Ruis, apud Poesía árabe y poesia europea, "Col. Austral", núm. 190, págs. 118-123. Lógicamente, coincidimos en algún punto (y no lo he querido eliminar de mi exposición), pero se trata de dos análisis hechos con pretensiones muy distintas. Vid., también, Devoto, op. cit., págs. 369-370.
} 
Los dos relatos son muy próximos y apenas difieren en las consideraciones morales. Sí, en cuanto a los planteamientos: Juan Ruiz pinta la escena de una manera directa: la zorra está hambrienta y el cuervo, en lo alto de un árbol, tiene un queso. De inmediato, la adulación. Don Juan Manuel se demora, el gran pedazo de queso había sido encontrado; el cuervo procedió racionalmente: para comérselo en paz, se subió a un árbol. Pero el zorro lo vio, desarrolló también su propio raciocinio. No trataba de adular ex abrupto, porque los halagos no surtirían efecto, sino que procedió con cautela: el cuervo sabe que no es hermoso; entonces el zorro saca a relucir las pretendidas fealdades y comparándolas con arquetipos de belleza (el pavón, la gacela) infiere de manera lógica que el ave tiene la hermosura de esos paradigmas de belleza. Los otros elementos de referencia son triviales y cumplen, con su trivialidad, un fin lleno de eficacia: aislar las dos valoraciones sobresalientes; sólo dos para que no haya comparación desmesurada.

Así las cosas, la zorra del Arcipreste intenta escuchar la voz del cuervo porque, y es un recurso de eficacia segura, está triste, y el canto le devolverá el gozo. En don Juan Manuel, se recurre a un recurso objetivo, no menos eficaz que el sentimental: Dios, sabiduría suprema, no procede por incoherencia, sino que habiendo hecho tener al cuervo condiciones excelsas en unas cosas, sobresalientes en otras, lo habrá hecho, también, buen cantor. Pero todo lo demás se ve (el color, la mirada), se sabe (pico y garras son mejores que los de las aves semejantes, no que los de todas las aves) y se ha experimentado (al volar adelanta a los pájaros). Sólo hace falta escuchar.

En ambos casos los resultados son idénticos, pero han seguido caminos distintos: en Juan Ruiz, la vanidad ciega al cuervo y el zorro se come el queso; en el Infante, hay un proceso de lógico raciocinio: no todo lo que se ha dicho de él es bueno (cierto que se han silenciado fealdades absolutas para establecer cotejos convenientes), ni supremo ; más bien ha habido comparaciones y referencias limitativas. No, lo que se ha escuchado no son halagos gratuitos: antes bien, los informes desapasionados de un amigo. El cuervo de Juan Ruiz ha sido tocado en su estupidez; el de Juan Manuel, en su intelecto: ha sido engañado, y no sospecha el engaño. El zorro no se come el queso, sino que se lo lleva. Con lo que el relato cobra un carácter circular, y se vuelve al principio: el queso ha sido el móvil de toda la historia. Se empezó con el deseo de comérselo tranquilamente y ahora el zorro de don Juan Manuel se va - también- a buscar el escondrijo donde pueda quedarse en paz.

Son dos aspectos totalmente distintos de un mismo relato. El cuervo, en el Arcipreste, es una criatura infatuada, vacua, estúpida. De tales cua- 
lidades se aprovecha el zorro: no necesita sutilezas; recurre al halago directo y todo resulta rápido y eficaz. En la otra fábula el cuervo tiene, sí, vanidad, pero no es un necio, sino que sopesa el valor de los enunciados y, cuando posee la apariencia de la verdad, es cuando se decide a actuar. En el primer caso, el zorro es listo; en el segundo inteligente, y saca a colación una serie de virtudes positivas: astucia en el proceder, cautela en el elogiar, serenidad al exponer. Como resultado, las motivaciones, últimas del final común: razones subjetivas y razones objetivas bien contrapuestas en ambos escritores.

La lengua, también, al servicio de lo que los narradores han pretendido. Juan Ruiz ha pintado un cuadro divertido y en él las palabras están al servicio de los intereses. No se trata de una zorra, como designación de una especie bien conocida de depredadores, sino de una marfusa, es decir, de una 'astuta', o de una gulfara (1436 d) o una gulhara (1441 c), acaso, 'haragana'. En el fragmento que nos ocupa, ni una simple denotación del animal, sino unas versiones connotativas, mientras que don Juan Manuel únicamente raposo, el término no marcado. Juan Ruiz procede desde una desaforada comparación ("del cisne eres pariente: en blancura e en dono, fermoso, reluziente") y ya en el disparadero, una teoría de aves prestigiosas (calandria, papagayo, ruiseñor, gayo). Paralelamente, la algarabía de aquel mundo pajarero: cantar, gritar, gorjear, graznar y la voz que se levanta en un solo ("començó a cantar, la su boz a erzer"). Frente a este abigarrado guirigay, don Juan Manuel procede con un discurso lleno de austeridades: el negro es negro sin más, y sólo cuando hace falta surge la comparación reducida a un pavón o a una gacela; el resto se reduce a "ninguna aue tamanna como vos", "otra aue non puede fazer tan ligeramente", "cantar mejor que ninguna otra ave", "avrio el pico para cantar". Es todo: un cuadro de precisiones $y$ un enunciado general en el que nada necesita descender a un mundo concreto.

Una vez más, dos posturas que difieren en sus planteamientos intelectuales $y$, necesariamente, se tienen que valer de un instrumento lingüístico totalmente distinto. $\mathrm{Y}$ acaso no sea inútil que el Arcipreste de Hita ha dejado a cada criatura en su mundo, cada una con su nombre y su atributo cantoril, mientras que el infante don Juan Manuel ha hecho que los seres, en su abstracción genérica, se encuentren subordinados a ese cuervo al que confiere dignidad humana y lo llama don. Y sería un nuevo resultado: el ejemplo desenfadado en un mundo variopinto o la validez escueta de la realidad animal en el mundo preciso de los hombres.

Poco después de empezar nuestro siglo (1905), Karl Vossler publicó su Sprache als Schöpfung und Entzicklung, donde estudió esta misma fábula 
en la elaboración de La Fontaine ${ }^{10} \mathrm{y}$, después, adaptó y amplió su análisis en La Fontaine y sus fábulas ". Creo que cualquiera de nuestros textos supera al del poeta francés: por coherencia en el relato, por precisión en los matices, por desarrollo intelectual, por estructuras bien trabadas. $Y$, aún más, la habilidad que Vossler pondera en La Fontaine al humanizar al cuervo (Maitre Corbeau) estaba ya en don Juan Manuel. Lejos de cualquier puerilidad, pero ahí están los dos textos, extraordinarios, del siglo xiv que acreditan el talante genial de sus creadores.

LA Historia DEL HOMBRE QUE VENDió SU ALMA AL DIABLO

Queda un último testimonio, el "enxiemplo del ladrón que fizo carta al diablo de su ánima":

Libro de Buen Amor

En tierra sin justicia, había ladrones $y$ el rey quiso restablecer el orden con severos castigos (1454).

Uno de los salteadores temió por su vida (1455).

y el diablo se le apareció para comprarle el alma, a cambio de su ayuda (1456).

Se hace el concierto (1457).

El ladrón robó un collar de oro y fue aprehendido (1457).

Llama al diablo que viene (1457) y le aconseja qué debe hacer (1459).
Conde Lucanor

Un rico se empobreció y cayó en tristeza (17-23).

Yendo muy afligido se encontró con el diablo, que le ofreció mejorarlo de su antigua condición (25-40).

Se hace el concierto y el hombre se convierte en ladrón (46-54).

El diablo le abre las arcas de un mercader (56-58).

Nuevos robos hasta que fue preso (59-63).

Llama al diablo que lo libra (64-68).

10 Traducción española de J. F. Pastor, Madrid, 1929, págs. 182-192. La fábula del zorro y el cuervo fue estudiada en un amplio marco románico por $\mathrm{H}$. Bihler en "Medium Aevum Romanicum". Festschrift für Hans Rheinfelder. Munich, 1963, páginas 21-46.

11 Traducción de Felipe González Vicén, "Col. Austral”, núm. 694, págs. 97-107.

12 Págs. 368-371. 
Pudo sobornar al alcalde (1460), que lo libró (1461).

Pero tanto siguió robando que el diablo se hartó de su pupilo (1463).

El ladrón, por su cuenta, quiso hacer como solía y, en vez de regalo, sacó una soga que dictaminó el juicio (1464).

El condenado ve y llama al diablo (1465) que prometió asistirle (1466) tras ayudar a un fraile (1467)

El diablo llega a la horca y se pone

Una vez el diablo no llegó, y el ladrón fue condenado a la horca (86-87).

El diablo le dio dinero para sobornar al alcalde (91-97), que acertó a librarlo (98-102), pero en vez de los maravedises encontró la soga para la sentencia (103-107).

El ladrón llamó al diablo, pero su poder sólo alcanzaba hasta el pie de la horca (108-110).

El ladrón murió ahorcado.

bajo el condenado para que haga pie (1468).

Los sayones creyeron que el ladrón estaba muerto y se fueron (1469).

Disputan el ladrón y el diablo (1470).

$\mathrm{El}$ condenado ve la horrible representación del demonio (1472) motivada por los muchos pecados del ladrón (1473-1474).

El diablo da un salto y hace que el ladrón se ahorque (1475).

Se trata de un relato algo más complejo que los anteriores, pero en ambos textos se pueden seguir bien las relaciones. Las discrepancias iniciales obedecen a dos posturas distintas: Juan Ruiz parte de un hecho general del que el ladrón no es sino una piececilla: el concierto entre él y su protector se limita a una prestación de ciertos servicios; más allá, el propio demonio está en desacuerdo con las tropelías de su protegido. La avaricia y torpeza del ladrón le hicieron caer en condena, de la que lo vino a librar la condescendencia del diablo que, harto de aguantar, acaba por liberarse de la sumisión en que se encuentra. Diriamos que la maldad no está en el demonio, sino en los hombres que la ejercen: el diablo busca almas para 
su redil, pero no admite la maldad continuada ni la independencia del pecador. Al fin y al cabo, él es hombre de palabra y trata de cumplirla, aunque un exceso de trabajo parece no halagarle mucho. Por eso preferiría que el pecador llevara una vida tolerable $y$, desde luego, que no le culpe a él de las tropelías ajenas. Cada uno es hijo de sus obras y no puede hacérselas cargar a los demás, aunque sea el propio diablo, por eso la disputa final, y el ahorcado queda como un garabato porque el demonio no puede servir de escabel, y recibir injurias. El cuentecillo es divertido: el liablo va a lo suyo, que es comprar almas para perderlas, pero es fiel a sus contratos: si el fraile quiere condenarse por tener una mujer, es asunto suyo; el demonio cumple con facilitar el encuentro. Si el ladrón está en apuro, el diablo en su compromiso llegará hasta a sujetarlo, pero no admite otras injurias que las de ser diablo. Todo tiene un aire de broma y diversión apicarada. En don Juan Manuel, no. No hay reinos ni desorden: basta un hombre empobrecido. El diablo ahora debe ser parte contratante y maestro; pero el aprendiz se le ha pasado de raya. No admite bromas como el diablillo de Juan Ruiz: va a la horca, finge un soborno y lo que da a su pupilo es la cuerda para que lo ahorquen. En el fondo, Juan Ruiz hubiera librado a todos esos personajillos que hacen que la vida sea divertida. Don Juan Manuel tiene unas ideas muy distintas del mundo: hay una organización que no se puede conculcar, y el porler del mal tiene unos límites. Entre el bien y el mal las barreras son claras y la transgresión se paga. Los personajes del cuentecillo son muy serios, porque están ahí convertidos en símbolos: el amor excesivo a las riquezas puede llevar al pecado (lo decía el propio don Juan Manuel) y el pecado es, sin más, el Mal. El demonio atrae al pecador incauto hasta que lo pierde. Sin contemplaciones y sin comprensión : se trata de otra forma paradigmática; es el Enemigo. Mal y Enemigo son tétricas presencias contra las que el Hombre debe luchar; si se acepta el pacto, no hay más salida que la condenación. El moralista ha asomado con su implacable rigor: "Assi perdio aquel omne el cuerpo et el alma, creyendo al diablo et fiando dél. Et çierto sed que nunca omne dél creyó nin fió que non llegasse a auer mala postremeria". Juan Ruiz ha puesto todo su talento, y el del demonio del cuento, para algo mucho más placentero: para que doña Garoza se entienda con el Arcipreste, y no usen de la Trotaconventos más de lo que la vieja puede dar.

Ante estas dos versiones del mundo, la lengua debe cumplir fines muy diversos. El Infante actúa como un curial que objetivamente expone los hechos: "non a en el mundo tan grand desventura commo ser muy mal andante el que suele seer bien andante", "los que mal quieren fazer siempre aborrecen la lunbre", "et assi perdió aquel omne el cuerpo et el alma, creyendo al diablo et fiando dél". La lengua es el instrumento adecuado 
para la expresión lógica: subordinativas con que, causales con ende, finales con para que, condicionales con si, consecutivas con ca, etc., el uso de los verbos arrastra arcaísmos como el imperfecto de subjuntivo con valor de indefinido o de imperfecto de indicativo (fuera 'fue; había sido'), el imperfecto en correlación con gerundio para indicar la acción en su desarrollo (iba muy triste... y yendo assi), el condicional con valor de imperfecto del futuro (para que gelo diria), el imperfecto de subjuntivo con un valor fundamentalmente aspectual (por bien cerrada que fuesse ['estuviera'], que él non gela abriesse ['abriría'] luego), las formas en -se con preferencia a $-r a$, etc. Un vocabulario objetivo, sin rarezas de ningún tipo: algún cultismo jurídico imprescindible ("las avenenşias fueron fechas", "començaron a fazer pesquisa", "dieron sentençia"), algún término de la jerga de los abogados ("fizieron sus posturas", "estando assi el pleyto", "tomó alça$d a$ "), que son necesarios para el fiel entendimiento del relato. $\mathrm{Y}$, por supuesto, la habilidad del narrador que maneja todos los recursos: en las explicaciones al margen (etopeya del hombre arruinado, temor al demonio que supera la posibilidad de enriquecimiento, nocturnidad de los robos), en el estilo directo, eficaz en una exploración emotiva (" $;$ A don Martin, sabet que esto non era juego, que vien vos digo que gran miedo he passado!"), en un razonamiento astutamente suasorio ("Amigos, ¿quién vio nunca que menguase soga para enforcar omne? Çierta mente este omne non es culpado, et Dios non quiere que muera, etc.") o en las explicaciones que apostillan el relato ("et commo el diablo sabe todas las cosas pasadas, etc.", "et bien ved que el diablo siempre cata tienpo para engannar a los omnes, etcétera", "et esto fazia el alcalde por lo librar, etc.”).

Frente a este cúmulo de pericias, Juan Ruiz ofrece las suyas, tan válidas como éstas, pero tan distantes de ellas. Válganos un ejemplo muy breve. El ladrón llama al diablo (= don Martín en el cuentecillo del Infante) y le cuenta los miedos que ha pasado: "Et don Martin le dixo que estaua en otras grandes priessas et que por eso tardara". Todo friamente funcional. En el Arcipreste, la misma situación lleva a esta cuaderna (la 1466):

Luego seré contigo, desque ponga un frayle

Con una frayla suya, que me diz: "I Trayle, trayle!"

Engaña a quien t'engaña e a quien te fay, fayle;

Entre tanto, amigo, vete con este vayle.

En ella, el divertido desgarro del demonio. No menos importante que salvar a un condenado es dar solaz a frailes con monjas. Pensamos en el arte coetáneo de las sillerías de Zamora o de Ciudad Rodrigo. Y la lengua no es la del abogado que expone, sino la de la monja ansiosa que suspira imperativamente por lograr saciarse. Y la frase proverbial "a quien te fay, fayle" da una carga de afectividad a un relato transido de emoción humana. 
Juan Ruiz contempla la realidad y la vive en una visión de precisiones: la comparación popular con las cosas de menos valor (pepiones), la fanfarronería de quien se siente inseguro ( ya yo só desposado con la forca!), los pormenores no descuidados (por furto ando desorejado, el ladrón fue en la cadena puesto), el comportamiento de los hombres (diógela callando, apartó al alcalle). La muerte del ladrón no es, como en don Juan Manuel, un hecho objetivo para pagar los pecados: ahora se trata de una riña entre fulleros, con lo que el relato no pierde el sesgo burlesco que mantiene desde la primera estrofa. En el moralista que es el Infante, el poder del mal termina en las antesalas de la muerte; en el Arcipreste, el mal es un añadido a la historia de ese par de pobres diablos que son el ladrón (incapaz de valerse por sí mismo) y el demonio (incapaz de ser otra cosa que un malhumorado discutidor). Es prodigiosa la capacidad creadora de Juan Ruiz: su vocabulario extensísimo, pero sin precisiones curialescas, porque en él la vida puede más que la particularidad de un metalenguaje; un vocabulario en el que se entremezclan toda clase de niveles para conseguir ese impresionante retazo de vida: arcaísmos (cras, far de prestar, malfetria, cadaldia), giros o voces familiares (diez tanto, de balde, engorres, fraila, a quien te fay, fayle, etc.), galicismos (ribalde, gran tiempo), sinónimos léxicos (don presente, alcalde - baile-adelantado), dobletes fonéticos (alcalde-alcalle) o morfológicos (saldrás - soterné), recursos como la paranomasia falló negro fallado. Si unimos a este abigarrado conjunto la reproducción literal de palabras ajenas o conversaciones, el humor con que se arrastra la atemorizada confesión ${ }^{13}$, la visión irónica de las cosas o el miedo de quienes menos debieran manifestarlo, tendremos una colección de motivos que nos dan el dominio lingüístico del Arcipreste para decir cuánto quiere y cómo lo quiere. Exuberancia, riqueza, extroversión, motivos todos que se manifiestan con una lengua a la que domina en todos sus registros y con la que construye -y gracias a su reiterada maestría - un cuentecillo inolvidable ${ }^{14}$.

\section{VALORACIón DE ESTOS RELATOS}

Don Ramón Menéndez Pidal había señalado las relaciones de Juan Ruiz y don Juan Manuel ${ }^{15}$ con unas fuentes latinas, que pudieron servirles, ellas

1s "Ya yo só desposado / con la forca, que por furto ando desorejado!" [...] Ante qu'el desposado penitençia pediese" (\$\& 1455 y 1456).

14 Para este relato, vid. Devoto, op. cit., pág. 449, y Ayerbe-Chaux, op. cit., páginas 7-13.

15 Para la cuestión de la transmisión de los cuentos populares y su coincidencia en autores diferentes, vid. IAN Micharl, The Function of the Popular Tale in the 
$\mathrm{u}$ otras semejantes, de antecedentes ${ }^{10}$ y Félix Lecoy se le habia anticipado en algún punto ${ }^{17}$. Trataré de ordenar estas cuestiones para mi propio análisis.

Los tres primeros relatos que he analizado pertenecen al Juan Ruiz fabulista y el último al Juan Ruiz cuentista ${ }^{18}$; tienen, pues, fuentes distintas y, en cuanto nos interesa, podemos ver cómo los narradores españoles elaboran personalmente los datos originales. Porque los informes de Lecoy no suelen ser otra cosa - y no es poco- que una referencia bibliográfica con unas valoraciones un tanto neutras: cle la golondrina y el campo de cáñamo (o lino) da el Romulus de Walter el Inglés como antecedentes, y añade; "le développement chez Juan Ruiz est seulement plus pittoresque" (pág. 131); el cuento de la zorra ladrona y el de la zorra y el cuervo no tienen valoraciones estéticas, aunque se nos dan en el libro del investigador francés eruditísimas observaciones, y en el de la historia del hombre que vendió su alma al diablo, se limita a decir: "Chez Juan Ruiz, par une déformation assez étrange, il semble que ce soit par pure lassitude que le diable renonce désormais à aider un criminel qui lui donne tant de mal" (pág. 155).

Creo que, para entender el arte de los dos escritores, la breve nota de Menéndez Pidal sigue siendo la mejor introducción; con razón, Corominas lo ha señalado en diversos puntos de su edición y puede servir como referencia. Yo he buscado un camino esencialmente lingüístico para conocer la conducta de ambos escritores; ahora me fijaré en qué deben, o se desvían, de los antecedentes que suelen aducirse. Debo insistir en que me baso en unas diferencias que sustentan unas determinadas selecciones de vocabulario; por eso sirven muy poco para mis fines análisis como el de F. Weisser, que busca la originalidad del Arcipreste en ciertos modos poéticos ${ }^{10}$, o el de Ubrich Leo, que persigue esa misma originalidad en la comparación del Libro de Buen Amor con alguna de sus fuentes ${ }^{20}$.

\section{LOS TEXTOS LATINOS}

Para Lecoy "la source de Juan Ruiz est le Romulus de Walter l'Anglais, on pourrait presque dire sa source unique" (pág. 118), y a esta com-

\footnotetext{
'Libro de buen amor', apud "Libro de Buen Amor Studies", edit. G. B. Gybbon-Monypenny, Londres, 1970, págs. 177-218.

16 Trabajo citado en la pág. nota 9.

17 Recherches sur le Libro de Buen Amor, París, 1938. Sobre este importante libro hay que ver - porque en ocasiones nos tocan de cerca- las observaciones de Leo Spitzer en la "Revista de Filología Hispánica", I, 1939, pág. 269, por ejemplo. 10 Según los índices de Lecoy.

10 Sprachliche Kunstmittel des Ergpriesters von Hita ("Volkstum und Kultur der Romanen", VII, 1934, págs. 164-243 y 281-348).

20 Zur dichterischen Originalität des Arcipreste de Hita, Frankfurt, 1958.
} 
pilación me voy a referir ${ }^{21}$. Con el número $\mathrm{XX}$ en las Fábulas de Walter aparece la que titula $D e$ Yrundine et Lino ${ }^{22}$. Son catorce versos sin gracia y sin ningún tipo de precisiones. El sembrador es Homo, la golondrina Hyrundo y los pájaros Aues; el resto, unos enunciados escuetos y sin la menor tilde de emoción.

El mismo argumento está en Romuli Anglici Nonnullius Exortae Fabulae (Hervieux, págs. 557 y 643), versiones en prosa, más disertas que la de Walter, sobre todo la segunda, pero que, ni de lejos, se pueden aproximar a la del Arcipreste. No me explico que ante estas insulseces la versión de Juan Ruiz, tan llena de vida, de conocimientos de la realidad, de lo que es el reconcomio acumulado y el sentido de la composición de un cuadro, le parezca, a Lecoy, "seulement plus pittoresque". No creo que éste sea el camino de la valoración crítica.

Menéndez Pidal señaló el Rómulo Anglico Completo (Romuli Anglici Cunctis) como antecedente del texto de don Juan Manuel (Hervieux, página 577), pero un cotejo de ambos nos permite formular las mismas afirmaciones que en el caso de Juan Ruiz: pobreza de recursos, sencillez del relato, ninguna complejidad en la conducta de los seres. Tampoco ahora la comparación tiene mucho color.

El cuento del raposo ladrón pertenece a la tradición oriental del Libro de los Siete Sabios (Lecoy, pág. 138) y, según el investigador francés, aun siendo desconocida la fuente que sirvió a los relatos españoles, parece que fue alguna emparentada con la griega y no con la versión árabe. De cualquier modo, los caracteres que he señalado mal pueden constar en una fuente: se trata de sendos procesos de creación para los que poco valor tiene un antecedente concreto. El valor de los relatos está en la manera de contar, no en la sustancia que se narra.

El tercero de los textos comunes (la zorra y el cuervo) es de una enorme riqueza documental: véanse las referencias de Lecoy (pág. 136, núm. 20). También ahora Walter el Inglés parece ser antecedente de Juan Ruiz, pues tiene la comparación con el cisne y algunos elementos léxicos ${ }^{23}$; mientras que el Rómulo Anglico Completo (Hervieux, págs. 322-323) sería el an-

21 Julio Puyol y Alonso trató de fijar, sin demasiada fortuna, algunas fuentes de Juan Ruiz, que ahora nos vendrian bien: El Arcipreste de Hita. Estudio crítico (Madrid, 1906, págs. 169-174). Véanse ahora las páginas esclarecedoras de Francisco Rodríguez Adrados, Aportaciones al estudio de las fuentes de las fábulas del Arcipreste ("Philologica Hispaniensia in honorem M. Alvar", III, págs. 459-473).

22 Cito por Ltopold Hervieux, Les fabulistes latins depuis le siecle d'Auguste jusqu'd la fin du moyen âge, t. II : Phedre et ses anciens imitateurs directs et indirectes, París, 1894, pág. 235.

es Lecoy, pág. 136; Mentendez Pidal, pág. 120. La comparación con el cisne consta también en las Gualterianae Fabulae (Hervieux, II, pág. 387). 
tecedente de don Juan Manuel por comparación con el pavo ${ }^{24}$. Creo que las coincidencias son mayores: el encuentro de la zorra hambienta con el cuervo en el árbol, la adulación directa sin preparativos, la vanidad del cuervo para iniciar el canto ("credit auis, picteque placent preludia lingue"), vergüenza del pájaro al perder el queso. Los elementos son los mismos, pero lo que Juan Ruiz nos ha regalado es un extraordinario cuadro de la realidad en la que él vive ${ }^{25}$. Todo lo que hemos considerado anteriormente es de su propia creación y nada debe al original. Es inútil comparar, porque carece de sentido oscurecer un texto oscuro con el brillo exultante de otro.

Si reducimos don Juan Manuel al Rómulo Anglico Completo los resultados serían idénticos a los que acabo de referir. El texto latino en prosa es tan modesto como el del verso, en tanto el cuentista español es tan ducho narrador como el Arcipreste, por más que proceda con mil otros recursos. No creo, sin embargo, que don Juan Manuel se haya inspirado en la fuente aducida por Menéndez Pidal, pues hay muchas diferencias (Hervieux, págs. 574-575) : en la aldea el cuervo había robado (furatus erat) con astucia un queso ${ }^{26}$ y se volvió al bosque a comérselo en lo alto de una encina; falta la cogitación de la zorra para apoderarse del queso; falta la forma noticiera de las buenas cualidades del cuervo; las comparaciones son distintas $y$ mucho menos matizadas en el original latino, falta el proceso intelectual por el que el cuervo se engaña; falta el no sospechar el engaño y sobra, sin embargo, la vanidad del cuervo ("Hiis igitur Vulpedem laudibus Corvus deceptus, ut Vulpi placere possit et ampliores laudes promereri, cantare cepit"). Es decir, todo difiere y sólo se mantiene la comparación con las plumas (no con la cola) del pavón ${ }^{27}$. De cualquier modo, don Juan Manuel ha creado una obra original con todas las bellezas a las que ya me he referido. $\mathrm{Y}$, desde luego, su personalidad ha quedado bien patente ante esa riqueza de matices y sutilezas con que ha enriquecido su relato.

Por último, nos queda el cuarto de los ejemplos comunes, que nada puede resolvernos por cuanto carecemos de unos antecedentes ciertos, y los informes de Lecoy (págs. 154-155) no ayudan a resolver las dudas.

Este minucioso recorrido creo que sirve para algo: nada de lo que los

24 Menendez Pidal, pág. 121.

25 Habría que situar esta descripción urbana dentro de una evolución muy precisa del pensamiento medieval tal y como señala Jaçues Le Goff en Pour un autre Moyen Age, París, 1977, pág. 164.

- En muchas ocasiones se dice que el queso fue robado de una ventana (Hervieux, II, págs. $11,136,168,201,236,250,265,423,459,480,521,558$, 664), en otras, simplemente, robado ( $b$., pág. 406). El motivo del robo de la ventana reaparece en Juan de Schepeya (Hervieux, IV, pág. 419).

27 No sé si a estas plumas habrá llegado un eco de la fábula De corvo qui invenit pennas pavonis (Hervirux, pág. 603).

LXVIII, $1 .^{\circ}-2 .^{\circ}-3$ 
dos grandes autores han creado depende de unas fuentes latinas. Tomaron, sí, un argumento y nada más. Luego, cada uno de ellos inventó su propio arte: algo que no existía en los originales. $Y$ esa es su grandeza, saber convertir en motivo de deleite estético lo que en el original no es más que un insulso relato. Parece necesario repetir aquí, por trivial que para otros investigadores sea, que la literatura es una cuestión de forma y no de contenido. Con éste, sólo se hubieran podido redactar, pongo por caso, las veinte versiones, que Hervieux edita, del cuento del raposo y el cuervo: todas igualmente desabridas, y cada una tan impersonal como la otra. Pero esos contenidos, tan poco agraciados en latín, los cogieron dos hombres geniales, los elaboraron, los recrearon y les dieron unas formas de expresión inconfundibles ya; a años luz de los textos que las motivaron y muy diversas entre sí. La literatura no es cuestión de ideas, sino de palabras, dijo Mallarmé a Degas. ¿Qué es lo pintoresco? ¿Saber contar? ¿Saber qué hacer con la lengua? ¿ Captar la realidad? ¿ Retratar el alma de las criaturas? Si esto es pintoresco, aquí tenemos dos grandes escritores pintorescos. Pero tal vez tengamos que buscar también nuevas formas a las palabras ${ }^{28}$.

Tampoco estoy más concorde con las conclusiones de don Ramón, por más que sus páginas sean -i i si son suyas!- sagaces y afortunadas. Ni creo que el Infante no supiera qué hacer con el texto de Walter el Inglés, ni creo que su fuente sea (en la fábula del cuervo y la zorra) el Rómulo Anglico Completo ${ }^{29}$. Ante una duda indemostrable y una certera negativa, creo que no podemos afirmar nada. Juan Ruiz y don Juan Manuel siguieron dos fuentes distintas, cierto, pero ¿no podemos pensar que el Arcipreste usó un texto en verso porque escribía en verso y el Infante uno en prosa porque escribía en prosa? La selección podría no ser temperamental, sino literaria, aunque claro está que la literatura exige diversidad de temperamentos, pero no es a éstos a los que me refiero. $\mathrm{Y}$ conste sin vacilaciones que uno y otro escritor alteraban las fuentes que les conocemos para proyectar su propia personalidad.

Ante la realidad que todos estos textos nos facilitan, mi conclusión es muy sencilla: las fuentes latinas no explican el quehacer de los dos grandes escritores. Son grandes escritores porque saben usar su lengua e inventar criaturas nuevas con motivos viejos. Si no tuvieran estas aptitudes serían tan adocenados como tantos y tantos repetidores con los que Hervieux ha llenado sus compactos volúmenes, y no es este el caso. Juan Ruiz y don Juan Manuel son creadores literarios porque uno observa la realidad ex-

\footnotetext{
- En justicia hay que decir que Lecoy supo captar los valores artísticos del Arcipreste (págs. 118-119).

20 Ayerbe-Chaux, sigue al gran maestro, aunque ofrece algunos "apuntes" a cosas que para mí son inexactas (op. cit., pág. 56).
} 
terna y el otro el alma de las criaturas, pero - y esto es lo fundamentalporque saben contar lo que han experimentado previamente, y nos tenemos que conformar con lo que a través de la lengua podemos descubrir ${ }^{30}$. Esto es lo que he intentado hacer. Pero, ante el silencio de los textos latinos, he de volver a lo que estos hombres me dieron cada uno desde su inalienable realidad.

\section{Conclusiones}

Los dos grandes escritores del siglo xiv usan cuatro ejemplos comunes, y ahí acaban las semejanzas. Don Juan Manuel narra desde planos de validez general, en ellos se mueve con precisión y orden; es decir, recurre a un discurso intelectual presidido por la lógica, pues tras los signos aparenciales vibran las exigencias de una doctrina ${ }^{31}$ o, como dijo María Rosa Lida, "don Juan Manuel permite vislumbrar las coordenadas de su universalismo y de su individualidad" ${ }^{32}$. Pero escribe ejemplos para edificar; de ahi su carácter admonitivo, su rigurosa moralidad, su implacable condena. Todo su discurso se mueve en un nivel de abstracciones (aves, hombres, causalidades) en las que Bien y Mal se reparten un mundo en el que los campos están muy bien deslindados. La lengua de que se sirve es una lengua objetiva, a la que domina, pero por la que no es dominado: dice lo que quiere y como quiere. Por esos caminos se llegará a la creación de un lenguaje riguroso, preciso $\mathrm{y}$, digámoslo, científico. Juan Ruiz no es un moralista, sino un hombre vital; para él todo es relativo y las abstracciones no existen. Ante la Castilla de su tiempo ve las cosas, y las ve muy bien, pero no gusta de la solemnidad ni de las palabras imprecisas: el Hombre es pajarero, cazador, redero y las aves, avutardas, calandrias, papagayos, ruiseñores, gayos, tórtolas o pardales ${ }^{23}$. Y ese hombre habita casas con puertas y ventanas, apiñadas unas junto a otras para hacer muros de defensa o callejas y caminos de ronda. Y los hombres que pululan por los pueblos son vecinos que tienen oficio, que saben menesteres, que viven sus propias inconsciencias. Naturalmente, nada más lejos de la ética que estos seres que

so No puedo utilizar en mi trabajo el estudio de R. B. Tate e I. R. Macpherson porque se limita a la descripción externa de ciertos aspectos de lengua (edic. del Libro de los Estados, Oxford, 1974, págs. LXVI-XCII).

31 Cfr. Marfa Ana Diz, Patronio y Lucanor: la lectura inteligente "en el tiempo que es turbio". Potomac, 1984, pág. 170.

32 Estudios de literatura española y comparada, Buenos Aires, 1966, pág. 133.

ss Otros caminos de acercamiento a la creación lingüística de Juan Ruiz no resultan practicables (vid. Gonzalo Sobejano, El epiteto en la lirica española, Madrid, 1956, pág. 190). 
son como son y no como debieran ser: don Juan Manuel ve desde fuera $y$ juzga; Juan Ruiz se mete en sus criaturas y deja las cosas en su sitio. No hay una Verdad, sino infinitas verdades, normalmente acomodadas a cada deseo particular, y la vida -entonces- es un retablo heterogéneo en el que cada figura es un monigote que representa lo mejor que puede su propio papel : desde la golondrina burlada por las otras aves, al diablo humanísimo, pasando por esa zorra que resulta ser una prodigiosa actriz. Por eso las reacciones de estas figuras nada tienen de infra o suprahumanas, son simplemente humanas: gozo por el mal ajeno cuando nuestro consejo es desatendido, aceptación del daño hasta un nivel muy preciso, o límites tras los cuales la tolerancia se enfrenta con el abuso. Creo que esto apoya la idea de Antonio Prieto de que el autor está fuera de los relatos y puede "asegurarse en su hoy conflictivo" s4, que es ese presente desde el que narra, pero que -a mi modo de ver- establece una distancia entre el artista y los hechos: no hay un compromiso del autor con su obra, sino la abstracción que da el distanciamiento y que obliga a manejar un léxico de valores absolutos y no de realidades concretas. La lengua es muy otra en Juan Ruiz: en el saco sin fondo de sus posibilidades cabe todo; mejor, todo lo que sea espejo de la vida. Y ese infinito fluir hacia la obra de arte crea un tipo lingüístico también muy español: llevará a la Celestina, a la picaresca, al Quijote. La lengua en los dos grandes escritores es libertad. Han dicho lo que tenían que decir y nos han dejado dos mundos totalmente distintos, porque los hombres que los crearon en muy poco, o nada, se parecían ${ }^{35}$.

st Morfología de la novela, Barcelona, 1975, pág. 402.

ss Menéndez Pelayo señaló que nuestros dos escritores crearon, por vez primera, sendos estilos personales (Orígenes de la novela, I, pág. 150, de la Editora Nacional). 